\title{
JOURNAL OF BUDDHIST ETHICS: A SCIENTOMETRIC STUDY
}

\author{
Adhe Anil Pandurang \\ Research Student, Department of Library and Information Science, \\ Dr. Babasaheb Ambedkar Marathwada University, Aurangabad, India \\ Prof. Vaishali Khaparde \\ Professor and Head, Department of Library and Information Science \\ Dr. Babasaheb Ambedkar Marathwada University, Aurangabad, India
}

\begin{abstract}
The study is based on the Scientometric analysis of 209 research article published on journal of Buddhist ethics during the periods of 2005-2014. This Study will review on length of the title, numbers of pages, type of document, chronological distribution of article, no of references print as well as web references authorship pattern, author productivity and further it reveals Majorities 109 articles are published by USA contributors followed by UK and alternative contributors. The findings reveal various aspects of the characteristics and patterns of contributions of the study.
\end{abstract}

Key words: Scientometrics, Buddhist ethics

Cite this Article: Adhe Anil Pandurang and Vaishali Khaparde, Journal of Buddhist Ethics: A Scientometric Study, International Journal of Library \& Information Science, 8(3), 2019, pp. 26-38.

http://iaeme.com/Home/issue/IJLIS?Volume $=8 \&$ Issue $=3$

\section{INTRODUCTION}

\subsection{Scientometrics}

Scientometrics is the science of measuring and analyzing science. In practice, Scientometrics is often done using Bibliometrics which is a measurement of the impact of (scientific) publications.

\subsection{Definition Analysis}

\subsubsection{Scientometrics}

According to bankapur, M.B. and Kumabar, (1993) "Scientometrics is a more general that Bibliometrics. It is interesting to know, that both disciplines have a large overlap. It is surprised to learn certain comments stating that both disciplines have a large overlap. It is 
surprised to learn certain comments stating that Scientometrics, using Bibliometrics techniques id a part of Bibliometrics".

\subsubsection{Scientometric Analysis}

According to (2006), wouters, a cart intension has always existed between academic Scientometrics and political /practical, Scientometrics, the letter of which has been described as a hybrid of social science and bur rerate expertise (2006).

\subsection{Journal of Buddhist Ethics}

The Journal of Buddhist Ethics is the first academic journal dedicated entirely to Buddhist ethics. We promote the study of Buddhist ethics through the publication of research and book reviews and by hosting occasional online conferences. Our subject matter includes:

- Vinaya and Jurisprudence

- Medical Ethics

- Philosophical Ethics

- Human Rights

- Ethics and Psychology

- Ecology and the Environment

- Social and Political Philosophy

- Cross-cultural Ethics

- Ethics and Anthropology

- Interfaith Dialogue on Ethics

\subsection{Review of Literature}

(Alhamdi, Khaparde \& Shesharao, 2014) They conducted a Scientometric analysis of 56 papers published in the Library and Information science \& Technical Abstract (LISTA) on internet use in the subject of library \&Information science during the period $2004-2013$. The study focused on various aspects: such as document types, growth Rate (GR) and doubling time (DT) of publications and citations, year-wise, authorship pattern, institutions involved, most prolific authors of the journal. The study revealed that most of the papers $(71.4 \%)$ of papers were contributed by multiple authors. USA is the top producing country with 8 $(14.3 \%)$ publications of the total output. All the articles were published in English language.

Khaparde V S (2011) she studied the pattern of information use by researcher in the field of library and information science. It is based on the references. appended to International Journal of "Library Hi Tech" during 2005-2009. The present study is based on 3876 references appended to 247 articles contributed by the authors in Library Hi Tech. In Authorship pattern it was found that Solo Research is Predominant than Collaborative Research. The degree of research collaboration was calculated and it was found that the single authorship trend increased gradually in Library Hi Tech.

Khaparde V S and Pawar (2013) studied the authorship pattern and author's collaborative research in Information Technology with a sample of 17917 articles collect from LISA during 2000-2009.The average number of authors per article is 1.80. In the study the degree of collaboration (C) during the overall 10 years (2000-2009) is 0.71 , but the year wise degree of collaboration is almost same in all the years of mean value 0.49 . According to 10 years of period, the multi- authorship articles are higher and predominant on single authorship. The study found that the researches in Information Technology are keep toward team research / group research rather than solo research. 
Khaparde V S (2013) her paper conducted the Bibliometric Analysis of Research Publication of Department of Chemistry, Dr. Babasaheb Ambedkar Marathwada University, from 1975 to 2012.774research publications were analysed from 144 journals. The study examines year-wise distribution of papers, authorship pattern, journal in which author publish. Results revealed that the number of publications was increasing consistently from 1975 to 2012. Out of 774 , there are $25 \%$ of publications made in 2009,2010 , and 2011 . The majority of the publications are made with 4 author and majority of the research paper published in journal of heterocyclic chemistry.

Vijay K R \& Raghavan I [7] analyzed the Journal of Food Science \& Technology published during $2000-2004$ and found that above $93 \%$ of contributions were by multiple authors.

A Scientimetric Analysis on Indian Journal of Physics was made by Nattar S [8] during $2004-2008$ which revealed that the year 2004 records the highest \% of contributions regarding single, two and three authored.

Kannappanavar B U, Swamy C \& Vijay Kumar M [9] analyzed the publishing trends of Indian Chemical Scientists during 1996 - 2000, which revealed average number of authors per paper has increased from 7.52 to 8.39 .

An attempt was made by Tilak Hazarika, Kusuma Goswami \& Pritimoni Das [10] to analyze the contributions of Indian Forestor which found Degree of Collaboration was 0.64 among the authors.

Guan \& Ma [11] examined the China's Semiconductor Literature and found mega authored papers records the higher value for Co-Authorship Index.

Senthamilselvi \& Srinivasa Raghavan [12] analyzed the issues of IEEE Trans on Power Electronics published during $2006-2008$ which revealed that maximum number of papers was published between $6-10$ pages category.

A bibliometric study has been carried out by Kalyane V L and Sen B K [13] on the Journal of Oilseeds Research published during 1984 - 1992 which revealed that the keyword "Groundnut" tops the list with 53 records.

Sanni S A and Zainab A N [14] examined the contributions published in Medical Journal of Malaysia during $2004-2008$ and found 4.82\% (28) of contributions were published by Malaysian authors with foreign collaboration.

\section{OBJECTIVES OF THE STUDY}

The primary objective of this study is to understand the growth of Journal of Buddhist ethics and their research output in global during the period 2005 - 2014. More specific objectives are as follows:

- To study the year-wise distribution of articles

- To study the frequency of citations

- To study the mail domain of publications

- To identify the length of page per article

- To find out organization wise distribution of publication.

- To find out country-wise distribution of articles.

- To find out the authorship pattern in the publication.

- To find out the reference of the article (Print as well as Web). 


\section{HYPOTHESIS}

The following hypotheses are formulated for the present study.

- Majority of the contributions are contributed by Single Authors.

- USA is the high productive country.

- Majority of the references are print references.

\section{SCOPE AND LIMITATION OF THE STUDY}

The present study is based on the Scientometrics Profiles of journal of Buddhist ethics. The present study is based on over all 209 articles during 2005-2014.

\section{DATA COLLECTION}

Data can be numerically expressed that is quantified quantifiable or objective (Fasibs off and Dely, 1990) the data was collected from journal of buddist ethics, with the help of SPSS.Total 209 articles, during 2005-2014.

\section{DATA ANALYSIS AND INTERPRETATION}

Scientometrics analysis is a branch of bibliometrics. It is an important research tools for understanding of the subject it aims at measuring the utility of documents and relationship between documents and fields.

The present study is based on the Scientometrics Profiles of journal of Buddhist ethics during 2005-2014. The present study is based on over all 209 articles during 2005-2014.

\subsection{Year-Wise Distribution of Contributions}

The year wise Distribution of contributions is shown in Table No.1

Table 1 Year-Wise Distribution of Contributions

\begin{tabular}{|c|c|c|}
\hline Year & Frequency & Percentage (\%) \\
\hline 2005 & 16 & 7.65 \\
\hline 2006 & 16 & 7.65 \\
\hline 2007 & 11 & 5.26 \\
\hline 2008 & 20 & 9.56 \\
\hline 2009 & 7 & 3.34 \\
\hline 2010 & 16 & 7.65 \\
\hline 2011 & 29 & 13.87 \\
\hline 2012 & 23 & 11.00 \\
\hline 2013 & 36 & 17.22 \\
\hline 2014 & 35 & 16.74 \\
\hline Total & 209 & 100.0 \\
\hline
\end{tabular}

It can be observed from the table No. 1 \& Figure no. 1 out of the total 209 contributions majority of the contributions i.e. 36 contributions were contributed in 2013 were as minimum contributions i.e. 07 contributions were contributed in 2009. 


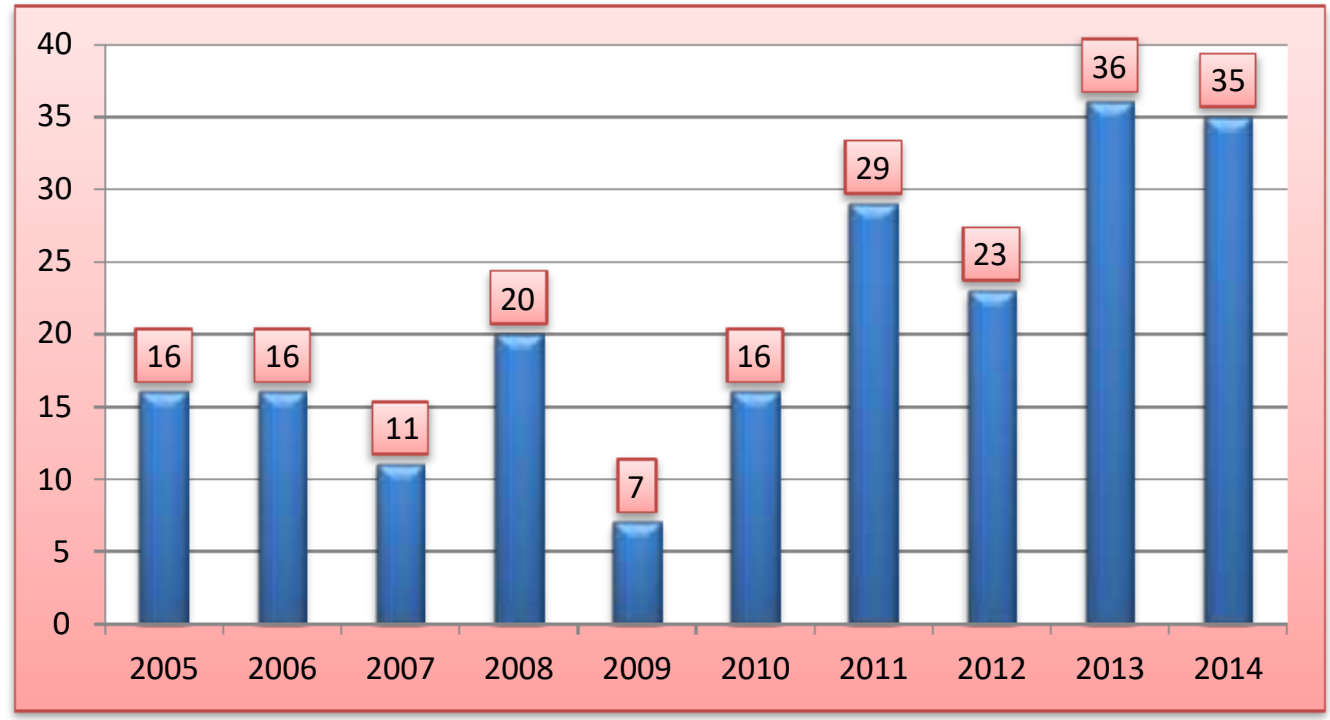

Figure 1 Distribution of contributions (year-wise)

\subsection{Authorship Pattern of Contribution}

The Authorship pattern of contributions is shown in Table No.2

Table 2 Authorship pattern of contributions

\begin{tabular}{|c|c|c|c|}
\hline Sr & No. of Authors & Frequency & Percentage (\%) \\
\hline 1 & single Author & 201 & 96.17 \\
\hline 2 & Two Author & 8 & 3.8 \\
\hline \multicolumn{2}{|c|}{ Total } & 209 & 100 \\
\hline
\end{tabular}

The distribution of Authorship pattern is given in the Table No.2. The table shows the multi authorship is predominant then single authors. Table No. 2 \&Figure no. 2 indicates the majority of the contributions are contributed by Single author. In which hypothesis no.01 is valid. "Majority of the contributions are contributed by Single authors" Table no, 2.

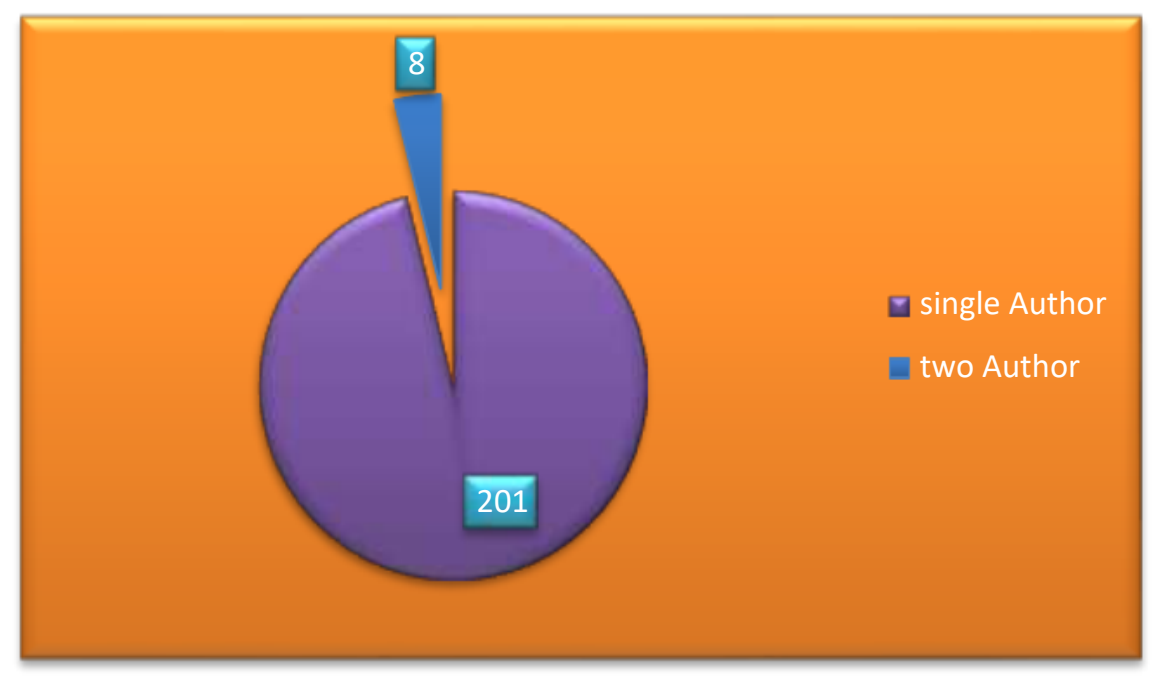

Figure 2 Authorship pattern of contributions 


\subsection{Author Wise Distribution of Article}

Table 3 Author wise distribution of article

\begin{tabular}{|c|l|c|c|}
\hline Sr & \multicolumn{1}{|c|}{ Author name } & frequency & Percentage (\%) \\
\hline 1 & Ven. Pandita & 5 & 2.39 \\
\hline 2 & Riccardo Repetti & 5 & 2.39 \\
\hline 3 & Analayo & 4 & 1.91 \\
\hline 4 & Christopher Ives & 4 & 1.91 \\
\hline 5 & Damien Keown & 4 & 1.91 \\
\hline 6 & Martin Kovan & 4 & 1.91 \\
\hline 7 & Bhikkhu Analayo & 3 & 1.44 \\
\hline 8 & Ven. Analayo & 3 & 1.44 \\
\hline 9 & Peter Harvey & 3 & 1.44 \\
\hline 10 & Two time publication $(2 * 14)$ & 28 & 13.4 \\
\hline 11 & Single time publiation $(1 * 146)$ & 146 & 69.86 \\
\hline Total & & 209 & 100 \\
\hline
\end{tabular}

It can be observed from the table no 09 and figure there were two authors they had 5 publication name of these two author Ven. Pandita and Riccardo Repetti.then 4 author published 4 articles and 3 author published 3 articles 2 time publication were 14 authors and 146 author had only one publication.

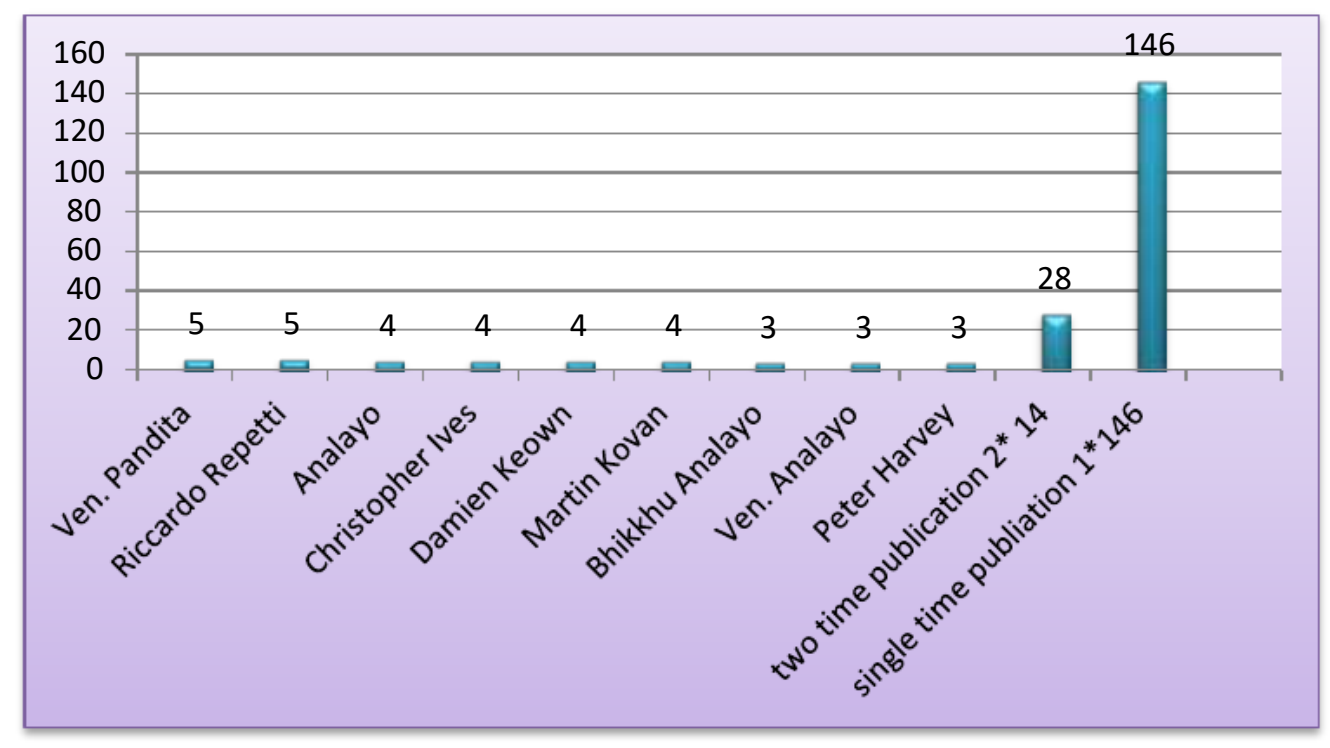

Figure 3 Author wise distribution of article

\subsection{Institution Wise Distribution of Article}

The distribution of article with sponsoring parental institution where from the collaborators contributed articles was analyzed and interpreted in the table no. 4 
Adhe Anil Pandurang and Vaishali Khaparde

Table 4. Institution wise distribution of Article

\begin{tabular}{|c|l|c|c|}
\hline Sr & \multicolumn{1}{|c|}{ Institutions } & Frequency & Percentage \\
\hline 1 & University of Kelaniya & 5 & 2.39 \\
\hline 2 & Not Mentioned & 4 & 1.91 \\
\hline 3 & University of Colorado, Boulder & 4 & 1.91 \\
\hline 4 & University of Melbourne & 3 & 1.44 \\
\hline 5 & University of New Mexico & 3 & 1.44 \\
\hline 6 & Devry University & 3 & 1.44 \\
\hline 7 & University of Tasmania & 3 & 1.44 \\
\hline 8 & Kingsborough College, CUNY & 3 & 1.44 \\
\hline 9 & Harvard University & 3 & 1.44 \\
\hline 10 & Two time publication $2 * 18$ & 36 & 17.22 \\
\hline 11 & Single time publication institute $1 * 142$ & 142 & 67.94 \\
\hline Total & & 209 & 100 \\
\hline
\end{tabular}

The distribution of published papers by institution wise the table 3 reveals that, out of 209 contributors, the highest number $5(2.39 \%)$ of contributors are contributed form the University of Kelaniya. The University of Colorado, Boulder stands the second place with $4(1.91 \%)$ contributors. There six institutes were stands the third place with 15 contributors. The $4(1.91 \%)$ contributors has not mention there institution, the $18(17.22 \%)$ institution stands on fourth place with two publication, the 142(67.94\%) institution stands on five place with one publication.

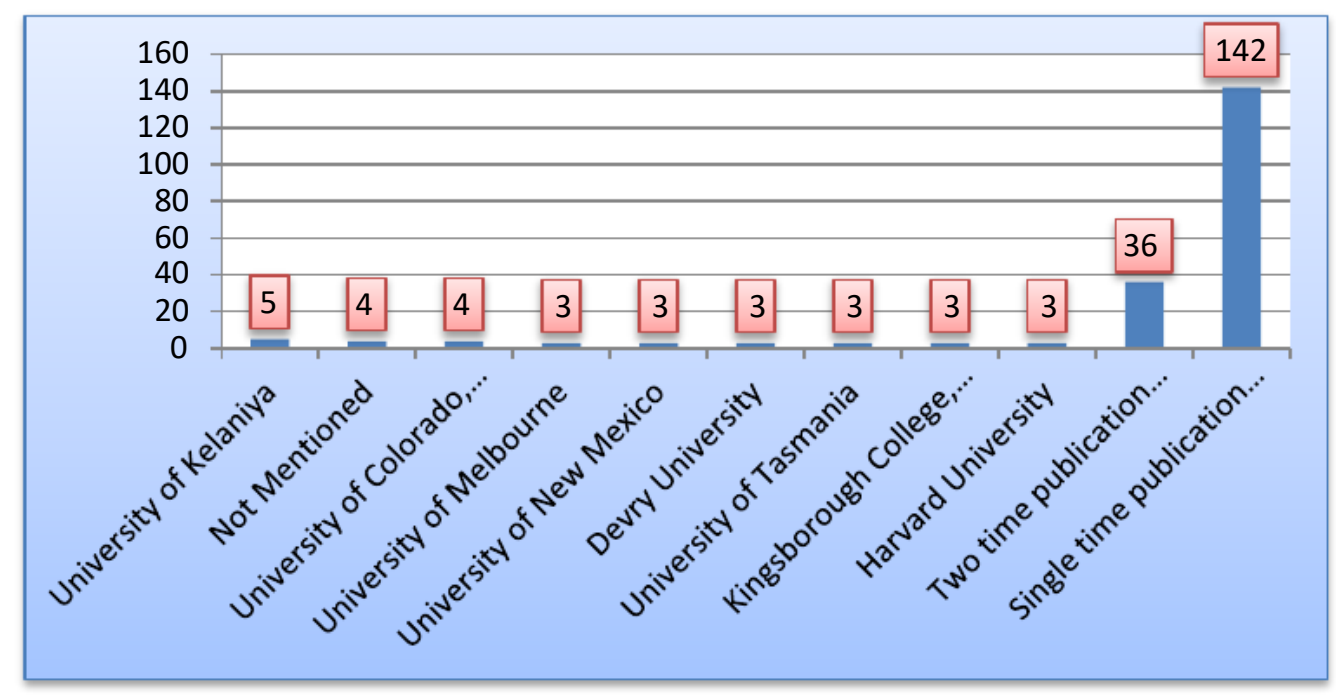

Figure 4. Institution wise distribution of Article

\subsection{Country Wise Distribution of the Article}

Table 5. Country wise distribution of the article

\begin{tabular}{|c|l|c|c|}
\hline Sr.No & Name of country & Frequency & Percentage \\
\hline 1 & USA & 109 & 52.15 \\
\hline 2 & United Kingdom & 17 & 8.13 \\
\hline 3 & Taiwan & 14 & 6.7 \\
\hline 4 & Australia & 10 & 4.78 \\
\hline 5 & Canada & 10 & 4.78 \\
\hline 6 & Sri Lanka & 6 & 2.87 \\
\hline 7 & Thailand & 5 & 2.39 \\
\hline 8 & Germany & 4 & 1.91 \\
\hline
\end{tabular}




\begin{tabular}{|c|l|c|c|}
9 & London & 4 & 1.91 \\
\hline 10 & Not mentioned & 4 & 1.91 \\
\hline 11 & India & 3 & 1.44 \\
\hline 12 & New York & 2 & 0.96 \\
\hline 13 & Philippines & 2 & 0.96 \\
\hline 14 & Belgium & 2 & 0.96 \\
\hline 15 & Japan & 2 & 0.96 \\
\hline 16 & Hawaii & 2 & 0.96 \\
\hline 17 & single time publication $\left(1^{*} 13\right)$ & 13 & 6.22 \\
\hline Total & & 209 & 100 \\
\hline
\end{tabular}

It can be observed from Table No. 4 the country wise distribution of contributors, the table 4 reveals that out of the total 209 contributors has contributed during 2005-2014, majority of article $109(52.15 \%)$ have been contributed form USA country. 04(1.91\%) contributors has not mention their country in the papers, $17(8.13 \%)$ contributors have been contributed form UK, $14(6.70 \%)$ contributors have been contributed from Taiwan, 10(4.78\%) contributors have been contributed from Australia and Canada, 6(2.87\%) contributors have been contributed from Sri Lanka, 5(2.39\%) contributors have been contributed from Thailand, 2 country contributed with 4 publication, 3 country contributed with 1 publication is India, 5 country contributed with 2 publication, and 13 country contributed with one publication. In which hypothesis no.o3 is valid. "Majority of the contributions are contributed by USA" Table no, 04.

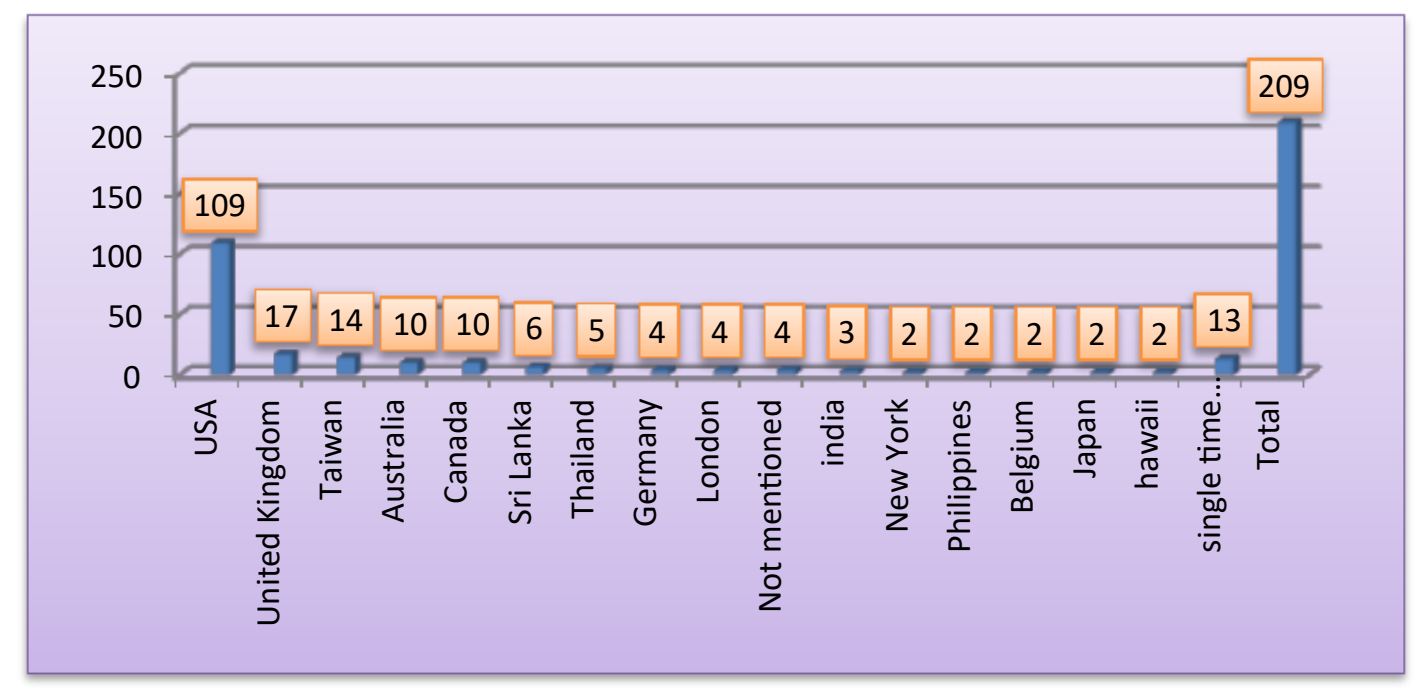

Figure 5. Country wise distribution of the article

\subsection{Email Domain Wise Distribution of the Article}

Table 6. Email domain wise distribution of the article

\begin{tabular}{|c|l|c|c|}
\hline Sr & \multicolumn{1}{|c|}{ Email domain } & Frequency & Percentage \\
\hline 1 & Gmail & 29 & 13.88 \\
\hline 2 & Not mentioned & 10 & 4.78 \\
\hline 3 & yahoo & 8 & 3.83 \\
\hline 4 & Dickinson & 7 & 3.35 \\
\hline 5 & hotmail & 6 & 2.87 \\
\hline 6 & Colorado & 5 & 2.39 \\
\hline 7 & buddhistethics & 5 & 2.39 \\
\hline 8 & Kingsborough & 5 & 2.39 \\
\hline
\end{tabular}




\begin{tabular}{|c|l|c|c|}
9 & devry & 4 & 1.91 \\
\hline 10 & gold & 3 & 1.44 \\
\hline 11 & unm & 3 & 1.44 \\
\hline 12 & Hawaii & 3 & 1.44 \\
\hline 13 & Two time publication email (2X17) & 34 & 16.27 \\
\hline 14 & Single time publication email (1X87) & 87 & 41.63 \\
\hline Total & & 209 & 100 \\
\hline
\end{tabular}

It can be observed from Table no. 5 there were as many as 29(13.88) authors used the gmail email domain. Followed by 8(3.83) authors used the yahoo email domain. 7(3.35) authors used the Dickinson email domain and 6 authors used the hotmail email domain like that five four three and two publication of the mail domain used 17 authors, and one publication of the mail domain used 87 and 10 authors not mentioned their email domain.

\subsection{Domain Name Wise Distribution of the Articles}

Table 7 Domain name wise distribution of the articles

\begin{tabular}{|c|l|c|c|}
\hline Sr & \multicolumn{1}{|c|}{ Domain name } & Frequency & Percentage \\
\hline 1 & edu & 112 & 53.59 \\
\hline 2 & com & 45 & 21.53 \\
\hline 3 & ac & 16 & 7.66 \\
\hline 4 & ca & 11 & 5.26 \\
\hline 5 & Not Mentioned & 10 & 4.78 \\
\hline 6 & org & 6 & 2.87 \\
\hline 7 & net & 4 & 1.91 \\
\hline 8 & single time publication domain (1X5) & 5 & 2.39 \\
\hline Total & & 209 & 100 \\
\hline
\end{tabular}

It can be observed from Table no. 6. There were as many as 112 authors used the edu. Domain name, and 10 authors has not mention their domain name in the papers, 45 authors used the com. Domain name, 16 authors use the ac. Domain name, 11 authors used the ca. domain name, 6 authors used the org. domain name, 4 authors used the net. And 5 authors used the domain name with one publication.

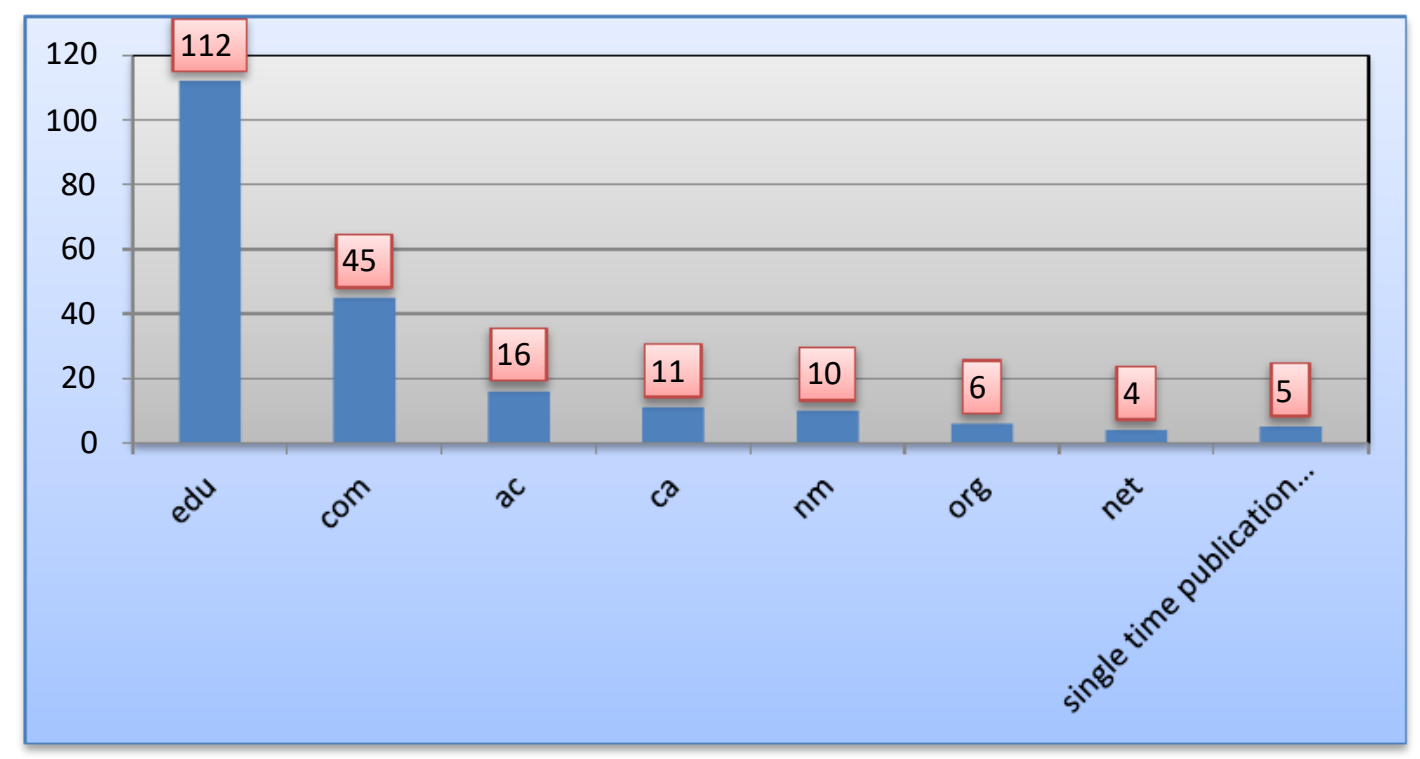




\subsection{Type of Document Wise Distribution of Article Domain name wise distribution of the article}

Table 8. Type of document wise distribution of article

\begin{tabular}{|c|c|c|c|}
\hline Sr & Type of document & Frequency & Percentage \\
\hline 1 & Article & 114 & 54.54 \\
\hline 2 & Review & 95 & 45.45 \\
\hline Total & & 209 & 100 \\
\hline
\end{tabular}

It can be observed from Table no. 7 the highest 114(54.54\%) number of publication has been published in research article in these study, and remaining 95(45.45\%) publication has review document type.

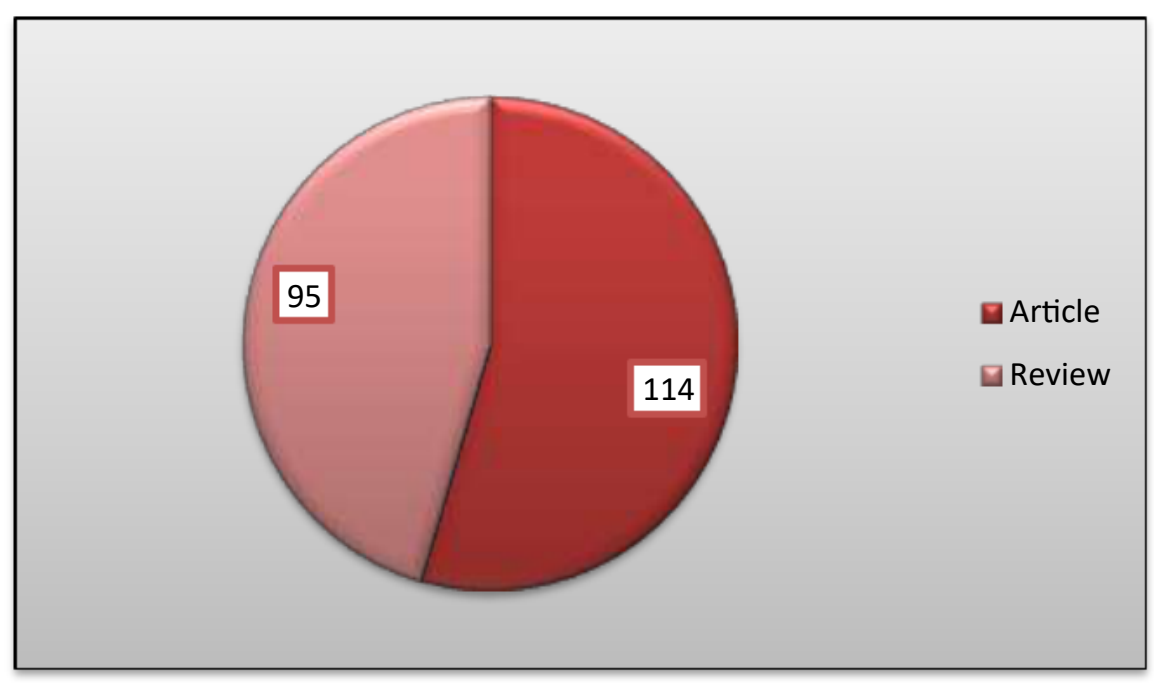

Figure 7 Type of document wise distribution of article

\subsection{No. of References Wise Distribution of Article}

Table 9 No. of References wise distribution of article

\begin{tabular}{|c|c|c|c|c|}
\hline year & $\begin{array}{c}\text { Print } \\
\text { References }\end{array}$ & $\begin{array}{c}\text { Web } \\
\text { References }\end{array}$ & $\begin{array}{c}\text { Total No. of } \\
\text { References }\end{array}$ & Percentage \\
\hline 2005 & 145 & 1 & 146 & 4.078 \\
\hline 2006 & 233 & 0 & 233 & 6.51 \\
\hline 2007 & 192 & 21 & 213 & 5.95 \\
\hline 2008 & 275 & 13 & 288 & 8.04 \\
\hline 2009 & 154 & 3 & 157 & 4.39 \\
\hline 2010 & 183 & 17 & 200 & 5.59 \\
\hline 2011 & 298 & 17 & 315 & 8.80 \\
\hline 2012 & 384 & 66 & 450 & 12.57 \\
\hline 2013 & 758 & 30 & 788 & 22.01 \\
\hline 2014 & 674 & 116 & 790 & 22.07 \\
\hline Total & 3296 & 284 & 3580 & 100.000 \\
\hline
\end{tabular}

It can be observed from the table no 08 and figure also maxim articles are from print references the majority print references in the year of 2013 were 758.amd then the minimum references are from web references total 284 web references in the duration of 2005 to 2014 and majority web references in the year of 2014 is total 116 web references are given there. In which hypothesis no.04 is valid. "Majority of the contributions are contributed by print references" Table no, 09. 


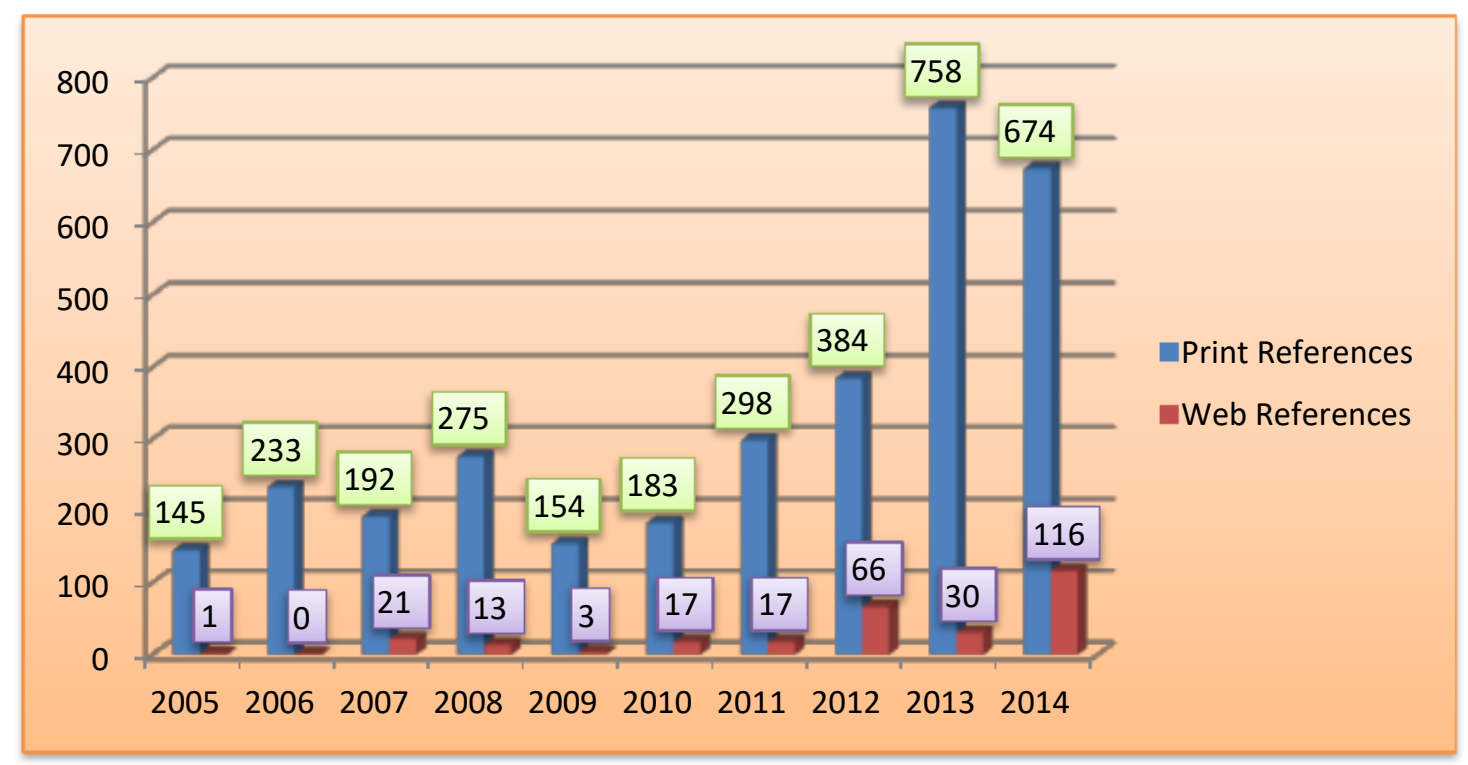

Figure 8.No of References wise distribution of article

\subsection{Length of Pages Wise Distribution of Article}

Table 10 Length of Pages wise distribution of article

\begin{tabular}{|c|c|c|c|}
\hline Sr & Length of Pages & Frequency & Percentage \\
\hline 1 & 00 to 25 & 130 & 62.2 \\
\hline 2 & 26 to 50 & 68 & 32.54 \\
\hline 3 & 51 to 75 & 7 & 3.35 \\
\hline 4 & 76 to 100 & 4 & 1.91 \\
\hline Total & & 209 & 100 \\
\hline
\end{tabular}

It can be observed from the table no 10 and figure no 08 the majority articles length of pages 130 articles publication from 0 to 25 pages. Then 68 articles were published from 26 to 50.then 7 articles published from 51 to 75 pages and remaining four articles were from 76 to more than pages.

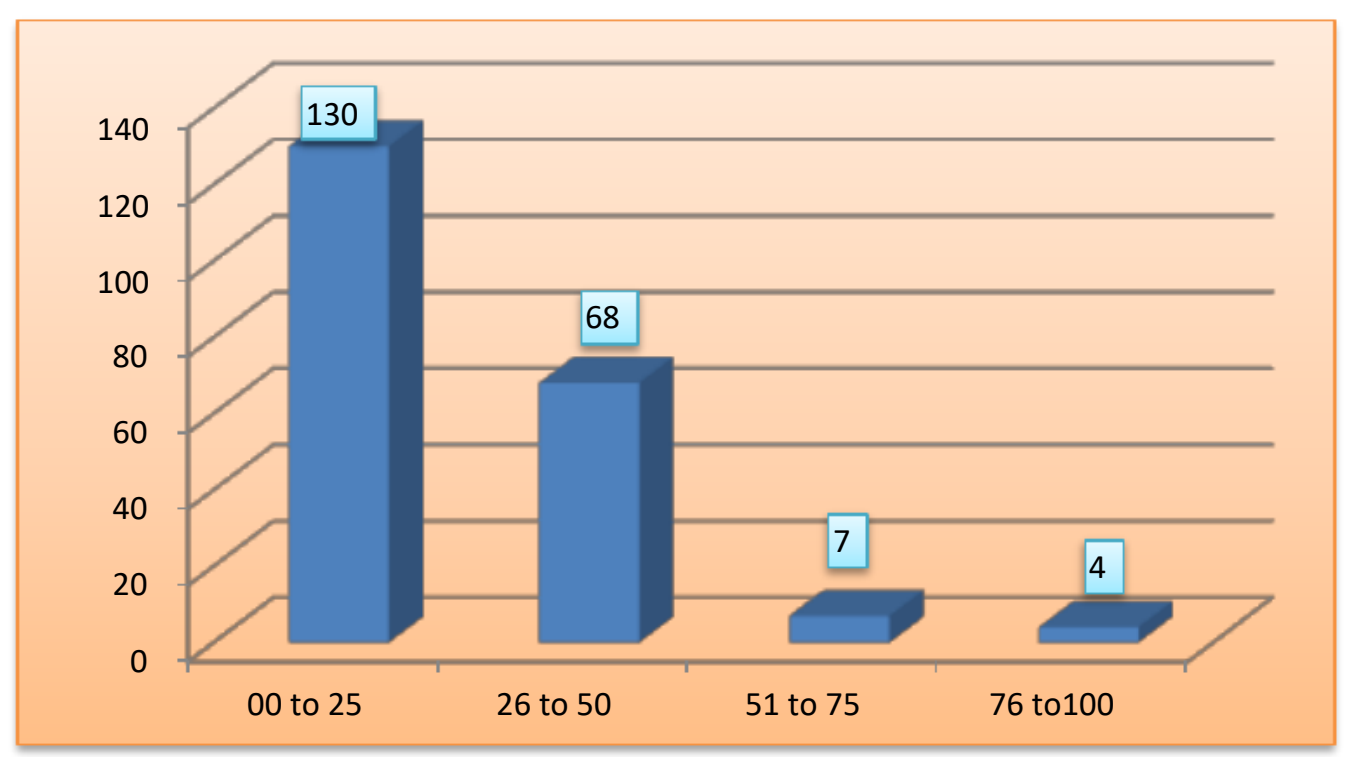

Figure 8 Length of Pages wise distribution of article 


\section{FINDINGS}

1. The highest numbers $36(17.9 \%)$ of papers were published in 2013 contributing.

2. More than two-thirds $40(71.4 \%)$ of papers were contributed by multiple authors.

3. Most productive authors are Ven. Pandita and Riccardo Repetti who had contributed 5 Papers.

4. Only University of Kelaniya contributed five times, while the other institution each Contributed once, two three and four time.

5. 28 countries carrying out research and produced 209 articles. USA is the top producing Country with 109 publications of the total output

6. The majority 130 of publications have citations from 00 to 25 .

7. Majority references are from print references.

8. Majority of web references are available in year 2014.

\section{CONCLUSION}

Scientometricis relatively new subject of information. It helps to evaluate information \& to handle the information in libraries and information centers by the quantitative analyzed information. It deals with the mathematical and statistical analysis. This is an umbrella term used for many studies where quantitative method or techniques are used to investigate various aspect of written document.

We concluded that the present study is based on buddhiest studies during the period of last ten years on the "journal of buddhiest ethics.this study is completed with the help of SPSS.this study is helpgful for researchs as well as buddhiest study.it is good and informative for the researcher.

\section{REFRENCES}

[1] Agrawal, Aruna, (1982): The reference frequency relation I Physical science. Scientometrics, 49(3).443-451

[2] Bankapur, M.B. and Kumabar (1993):Job satisfaction and publication output among librarians in Nigerian Universities. Library Management. 20(1), 39-48

[3] Derek, De.Solla. (2000). A study of learning and retention with a web-based IR interface journal of librarianship and information science 37(1), pp.7-16.

[4] Eugene, Garfield. (2002), Scientometric indicator data files. A multidimensional machine readable database for evaluative purposes. Scientometrics, 28(1993)137-150.

[5] Eva, Rodents. (2001), Advanced bibliometrics method as quantitative core of peer review based evaluation and foresight exercises, Scientometrics, 36(1)397-420

[6] Fasibs off and Dely (1990), Federal research impact assessment: Axioms, approaches, applications, Scientometrics, 34(1)163-206.

[7] http://blogs.dickinson.edu/buddhistethics/02/10/2015.

[8] http://www.ijodls.in/uploads/3/6/0/3/3603729/ramalingam8_79-89.pdf 
[9] Khaparde V. S. (2011). E-journals in library and information science: A Bibliometric study. International journal of Humanities and Social Sciences. Vol. 1(11) Special Issue August 2011 Center for promoting Ideas, USA.

[10] Khaparde V. S. (2011). Use of Internet by Research Scholars of Social Science Departments of Dr Babasaheb Ambedkar Marathwada University, Aurangabad. International Journal of Humanities and Social Sciences. Vol. 1(10) August 2011, Center for promoting Ideas, USA.

[11] Khaparde V. S.(2011) Pattern of information use by researchers in library and Information Science.International Journal of Humanities and Social Sciences. Vol. 1(12) September 2011 Center for promoting Ideas, USA.

[12] Khaparde V. S.(2011) Use of Information by Library Science Professionals: A Bibliometric Study. British Journal of Humanities and Social Sciences. Vol. 1(2) October, 2011, London, United Kingdom,78-90 ISSN 2048-1268.

[13] Khaparde V. S(2011) . Bibliometric study of Electronic Journal of Academic and special Librarianship.British Journal of Humanities and Social Sciences. Vol. 1(2) October, 2011, London, United Kingdom, 33-43 ISSN 2048-1268.

[14] Khaparde V. S(2011). Information Usage of Biological Science Researchers of Dr. Babasaheb Ambedkar Marathwada University, Aurangabad. International Library Movement, Vol.33 (2) June, 2011,HolyTemple Library, Ambala, 64-71. ISSN 0970-0048.

[15] Manavalan, R., (1982), why author think their papers are highly cited. Scientometrics, 60(3), 305-316.

[16] Rajendran.P., Jeyshankar.R. and Elango.B. (2011)" Scientometric Analysis Of Contributions To Journal Of Scientific And Industrial Research" International Journal Of Digital Library Services; 02(1)1-11.

[17] Wasudevan, K.T., (1995).Datc sources for performing citation Analysis; an overview. Journal of Documentation.64(20,193-210.

[18] Wouters,(2006).Scientometrics Analysis. Journal of Library and Information Technology. $1(1), 5-9$.

[19] Yadav, Jaisi Ram, (1984): The J-shaped distribution of citednes.Journal of Documentation; 58(4), 383-395. 